\title{
Prognostic significance of c-Met, $\beta$-catenin and FAK in patients with hepatocellular carcinoma following surgery
}

\author{
XUE-YI GONG ${ }^{*}$, NING MA ${ }^{2 *}$, HONG-XU XU $^{3}$, FAN CHEN $^{2}$, XIAO-HUI HUANG ${ }^{2}$ and QIAN WANG ${ }^{1}$ \\ Departments of ${ }^{1}$ Hepatobiliary Surgery and ${ }^{2}$ General Surgical Laboratory; ${ }^{3}$ Laboratory of Medicine, \\ The First Affiliated Hospital, Sun Yat-Sen University, Guangzhou, Guangdong 510080, P.R. China
}

Received July 31, 2015; Accepted April 6, 2017

DOI: $10.3892 / \mathrm{ol} .2018 .7733$

\begin{abstract}
The present study aimed to investigate the prognostic value of specific molecular markers in patients with hepatocellular carcinoma (HCC) who had received surgery. Immunohistochemical analysis was used to measure the expression of hepatocyte growth factor receptor (c-Met), $\beta$-catenin and focal adhesion kinase (FAK) in patients with HCC. c-Met expression was identified to be high in patients with larger tumors, higher $\alpha$-fetoprotein (AFP) levels, higher Edmondson grades, portal vein invasion and higher tumor-node-metastasis (TNM) stages. FAK expression was high in patients with portal vein invasion, higher Edmondson grades and higher TNM stages. $\beta$-catenin expression was high in patients with larger tumors, hepatitis B virus (HBV) infection, portal vein invasion, higher Edmondson grades and higher TNM stages. Following multivariate analysis, FAK $(\mathrm{P}=0.002)$ and $\beta$-catenin $(\mathrm{P}=0.006)$ expression levels were demonstrated to be significantly associated with Edmondson grade. Additionally, the tumor size $(\mathrm{P}=0.009)$ and $\mathrm{HBV}$ infection status $(\mathrm{P}=0.002)$ were revealed to be associated with $\beta$-catenin expression. Kaplan-Meier survival curve analysis demonstrated that patients with HCC with higher FAK expression, higher $\beta$-catenin expression, portal vein invasion, higher Edmondson grades, higher TNM stages, younger ages and higher AFP levels had significantly poorer prognoses. Cox's regression analysis revealed that the survival period was correlated with the Edmondson grade, age, AFP level, and FAK and
\end{abstract}

Correspondence to: Dr Xiao-Hui Huang, Department of General Surgical Laboratory, The First Affiliated Hospital, Sun Yat-Sen University, 58 2nd Yat-Sen Road, Guangzhou, Guangdong 510080, P.R. China

E-mail: hxiaohui2006@126.com

Professor Qian Wang, Department of Hepatobiliary Surgery, The First Affiliated Hospital, Sun Yat-Sen University, 58 2nd Yat-Sen Road, Guangzhou, Guangdong 510080, P.R. China

E-mail: wangqian_dr@126.com

${ }^{*}$ Contributed equally

Key words: hepatocyte growth factor receptor, $\beta$-catenin, focal adhesion kinase, prognostic, hepatocellular carcinoma $\beta$-catenin expression. Univariate analysis of $\mathrm{c}$-Met, $\beta$-catenin and FAK identified a significant correlation between FAK and $\beta$-catenin $(P=0.015)$. Correlation analysis revealed no significant correlation between the three molecular markers, but $\beta$-catenin and $c$-Met were markedly correlated $(\mathrm{P}=0.052)$. No significant correlation between FAK, c-Met or $\beta$-catenin expression was identified. FAK and $\beta$-catenin expression demonstrated a correlation with a range of clinicopathological factors, and high FAK and $\beta$-catenin expression levels were identified to be correlated with a poor survival rate of patients with HCC. Thus, patients with higher FAK and $\beta$-catenin expression may require more aggressive therapy. The results of the present study suggest that FAK and $\beta$-catenin expression possess more prognostic value than c-Met expression in patients with HCC.

\section{Introduction}

Hepatocellular carcinoma (HCC) is the fifth most frequently occurring malignancy and the third leading cause of cancer-associated mortality worldwide (1). Treatments, such as surgery, including transplantation, have provided a possibility of cure; however, the high recurrence rate has resulted in a reduced long-term survival rate in patients with HCC (2). The overall survival rate of patients with HCC is $<10 \%$. $(3,4)$. Additionally, evaluation of the individual prognostic outcome may aid in guiding surgical and chemotherapeutic treatment. In the present study, the prognostic significance of three HCC-associated molecular biomarkers were evaluated.

$\beta$-catenin serves an important role in the $\mathrm{Wnt} / \beta$-catenin signaling pathway, and participates in the development and progression of HCC (5). Phosphorylated hepatocyte growth factor receptor (c-Met) triggers mitogen-activated phosphate kinase (MAPK) signaling through the Ras-Raf-MAPK kinase signaling pathway (6), and its overexpression is present in the HCC phenotype with poor differentiation and malignancy $(7,8)$. Activation of $c$-Met signaling and $\beta$-catenin mutations are frequent genetic occurrences observed in liver cancer initiation (9-11). Previous studies have reported that $\mathrm{c}$-Met and $\beta$-catenin are coactivated in $\mathrm{HCC}$, and possess a possible correlation with hepatic carcinogenesis $(12,13)$.

Focal adhesion kinase (FAK) is a nonreceptor tyrosine kinase that can be phosphorylated, and activated by growth factors and integrins $(6,9)$. Multiple downstream signaling 
pathways, including extracellular receptor kinase (Erk), protein kinase B (PKB or Akt) and Ras-related C3 botulinum toxin substrate (Rac) have been identified to be regulated by FAK (14). Thus, FAK activation can regulate the adhesion, motility, proliferation and survival of various cells types (14). In a variety of cancers, including breast (15), intestine (16) and brain (17) cancer, FAK has been demonstrated to be activated and/or overexpressed, thus promoting the progression and metastasis of the aforementioned cancer types. Additionally, in certain HCC studies, FAK has been demonstrated to be overexpressed in HCC specimens, suggesting that it serves a role in hepatocarcinogenesis $(18,19)$.

Although the association between HCC and these three molecules has been separately investigated, a recent in vivo study investigated the potential role of FAK in hepatocarcinogenesis, and it association with c-Met and $\beta$-catenin (3). In that report, the deletion of FAK in hepatocytes did not affect their morphology, proliferation or apoptosis rates. However, FAK deficiency significantly repressed MET/DN90-b-catenin (CAT)-induced tumor development and prolonged the survival of mice with MET/CAT-induced HCC. In the livers of mice with HCC and in HCC cell lines, FAK was demonstrated to be activated by c-Met, thus inducing Akt/Erk activation, cyclin D1 upregulation and tumor cell proliferation. CAT enhanced c-Met-stimulated FAK activation and synergistically induced the activation of the Akt/Erk-cyclin D1 signaling pathway in a FAK-dependent manner. In addition, FAK was demonstrated to be required for CAT-induced cyclin D1 expression in a kinase-independent manner (3).

Following the review of previous studies on FAK, c-Met and $\beta$-catenin oncoproteins, their correlation with HCC has been identified in a variety of studies $(12,13,18-22)$. However, the intercorrelation among them requires further investigation. Irrespective of the coactivation of c-Met and $\beta$-catenin in $\mathrm{HCC}$ or the FAK's potential role in regulation of tumors described previously $(3,12,22)$, those previous studies were mainly focused on identifying the underlying molecular mechanisms of c-Met/ $\beta$-catenin-driven hepatocarcinogenesis. By contrast, the present study aimed to evaluate the prognostic value of these three oncoproteins and the possible correlations with each other in patients with HCC.

\section{Materials and methods}

Patients. A total of 86 patients with HCC who underwent surgery were included in the present study. All information and tumor tissue samples were collected from the database of the Department of Pathology of the First Affiliated Hospital of Sun Yat-Sen University (Guangzhou, China). Patients with radically resected HCCs who received surgery between January 2004 and December 2008 were recruited. Patients who had been treated with transhepatic artery chemoembolization (TACE), percutaneous ethanol injection (PEI) or radiofrequency ablation (RFA) were not included in the present study. A total of 68 males and 18 females were recruited, with a mean age of 50.2 years (age range, 26-77 years). With respect to the basic liver disease preceding HCC development, 65 cases (78.3\%) of liver cirrhosis were identified. Hepatitis B surface antigen was positive in 73 patients and 3 hepatitis $C$ patients $(88.0 \%)$, and 10 patients (12.0\%) did not have any underlying liver disease. The median follow-up period was 28.5 months (range, 3-60 months). The current study was approved by the First Affiliated Hospital of Sun Yat-Sen University. Written informed consent was obtained from all patients.

Tissue sections. Paraffin tissue blocks from all resected HCC specimens were obtained for immunohistochemical analysis. Hematoxylin and eosin-stained slides were examined to identify normal and tumor tissue. The tissue sections were produced by placing single, $3-\mathrm{mm}$ cores of tumor or normal tissue in a recipient block with manually created holes.

The examined clinicopathological features of the HCCs included the gender, age, hepatitis infection, tumor size, tumor-node-metastasis (TNM) stage, histological differentiation of tumor cells according to the Edmondson and Steiner grading system (23), presence of liver cirrhosis, portal vein invasion, hepatic artery invasion, and microvascular invasion (Table I).

Immunohistochemical staining. Formalin-fixed paraffinembedded sections of tumor tissue that were obtained from the resected liver specimens of patients with HCC were cut into $3-\mu \mathrm{m}$ thick sections. The specific antibodies used, sources, dilutions and detection system (GTVisionTM III Detection System/Mo\&Rb; cat. no. GK500710; Dako; Agilent Technologies, Inc., Santa Clara, CA, USA) are listed in Table II. The detection system included three major reagents: Horseradish peroxidase-labeled secondary antibody (anti-rabbit/mouse), 3,3'-diaminobenzidine (DAB) buffer diluent and DAB stock solution (a dye). Antigen retrieval was performed with citrate buffer. Sections were placed in citrate buffer ( $\mathrm{pH}$ 6.0), heated at $95^{\circ} \mathrm{C}$ for $7 \mathrm{~min}$, removed from the heat for $10 \mathrm{~min}$ and subsequently heated at $95^{\circ} \mathrm{C}$ for $7 \mathrm{~min}$. Sections were left at room temperature to cool and washed three times with PBS (10 mM, $\mathrm{pH} 7.5 \pm 0.1$ ) for $3 \mathrm{~min}$ each. The sections were deparaffinized in xylene, and the xylene was subsequently removed using absolute ethanol. Endogenous peroxidase activity was blocked by treatment with $0.3 \%$ hydrogen peroxide for $10 \mathrm{~min}$ and normal goat serum (CWBIO, Beijing, China; catalog no. CW0130) for $1 \mathrm{~h}$ at room temperature. The sections were then incubated with the primary antibodies overnight at $4^{\circ} \mathrm{C}$. Then, sections were incubated with secondary antibodies for $1 \mathrm{~h}$ in room temperature. 3,3'-Diaminobenzidine tetrahydrochloride was used as a chromogen, and Mayer's hematoxylin counterstain was applied. Omission of primary antibody was used as a negative control. The distribution of staining for FAK, c-Met and $\beta$-catenin was semi-quantitatively assessed by the percentage of positively stained cells. Staining for FAK, c-Met and $\beta$-catenin was categorized into four groups as follows: $0(<5 \%), 1+$ $(6-25 \%), 2+(26-50 \%)$ and $3+(>50 \%)$ (Fig. 1). Two observers independently evaluated the staining results, and interpretation differences were resolved by consensus. Olympus CX23 light microscope (Olympus Corporation, Tokyo, Japan) was used (magnification, $\mathrm{x} 200$ ).

Statistical analysis. The SPSS statistical software (version 21; IBM Corp., Armonk, NY, USA) was used in the present study. The Fisher's exact test was used for categorical variables, and the logistic regression model was used for multivariate analysis. Cumulative overall survival and disease-free survival curves 
Table I. Clinicopathological characteristics of patients with hepatocellular carcinoma.

Clinicopathological characteristic $\quad$ No. of patients $(n=86)$

\section{Sex}

Male

68

Female

HBV infection status
(+)

(-)

AFP level, ng/ml

$<500$

$\geq 500$

Liver cirrhosis status

(+)

(-)

Size, cm

$<2$

$\leq 2-5$

$\leq 5-10$

23

39

$\leq 10$

Edmondson grade

I

II

III

IV

Microvascular invasion status

Portal vein invasion status

$(+)$

(-)

TNM stage

I

II

31

III

IV
TNM, tumor-node-metastasis; AFP, $\alpha$-fetoprotein; HPV, hepatitis B virus.

were constructed using the Kaplan-Meier estimator method, and survival curves were calculated using the log-rank test. Correlation factors that were identified as statistically significant were included in the Cox's multiple regression model. Correlation analyses were used to evaluate the correlation among the three molecular markers. $\mathrm{P}<0.05$ was considered to indicate a statistically significant difference.

\section{Results}

Immunohistochemical expression of FAK. High FAK expression was observed in 39/86 HCC cases and low expression was observed in $47 / 86$ HCC cases. The correlation between the overexpression of all three biomarkers and clinicopathological parameters of HCC are illustrated in Table III. Univariate analysis identified a significant difference between FAK overexpression and other clinicopathological factors such as the Edmondson grade, TNM stage and portal vein invasion (all $\mathrm{P}<0.001)$. Logistic analysis revealed a positive correlation between FAK expression and Edmondson grade $(\mathrm{P}=0.002$; Table IV).

Immunohistochemical expression of c-Met. High c-Met expression was observed in 54/86 HCC cases, and low expression was observed in 32/86 HCC cases. Univariate analysis identified significant correlations between c-Met overexpression, and portal vein invasion $(\mathrm{P}=0.032)$, tumor size $(\mathrm{P}=0.012)$, $\alpha$-fetoprotein (AFP) $(\mathrm{P}=0.014)$, poor histological differentiation (Edmondson grade) $(\mathrm{P}=0.001)$ and $\mathrm{TNM}$ stage $(\mathrm{P}=0.010)$. However, multivariate analysis identified no significant correlation between c-Met overexpression and clinicopathological factors.

Immunohistochemical expression of $\beta$-catenin. High $\beta$-catenin expression was observed in 52/86 HCC cases, and low expression was observed in $34 / 86$ HCC cases. Univariate analysis identified significant correlations between $\beta$-catenin overexpression, and tumor size $(\mathrm{P}<0.001)$, hepatitis $\mathrm{B}$ virus $(\mathrm{HBV})$ infection $(\mathrm{P}<0.001)$, poor histological differentiation (Edmondson grade) $(\mathrm{P}<0.001)$ and $\mathrm{TNM}$ stage $(\mathrm{P}=0.001)$. Multivariate analysis identified significant correlations between $\beta$-catenin overexpression, and $\mathrm{HBV}$ infection $(\mathrm{P}=0.002)$, Edmondson grade $(\mathrm{P}=0.006)$ and tumor size $(\mathrm{P}=0.009)$ (Table IV).

Survival rates, biomarkers and clinicopathological profiles Clinicopathological factors. The differences in survival rates of patients with mild expression or overexpression of the three biomarkers were evaluated. The Kaplan-Meier survival curves for $\leq 60$ months of follow-up are shown in Fig. 2. The Kaplan-Meier survival for patients with Edmondson grade III/IV vs. Edmondson grade I/II was significantly correlated with the survival period (mean survival period, 18 vs. 34 months; $\mathrm{P}<0.001$; Fig. 2A). In addition, the TNM stage (mean survival period, 19 vs. 35 months; $\mathrm{P}<0.001$; Fig. 2B), AFP levels (mean survival period, 24 vs. 32 months; $P=0.038$; Fig. 2C), portal vein invasion (mean survival period, 18 vs. 32 months; $\mathrm{P}=0.001$; Fig. 2D) and age (mean survival period, 21 vs. 30 months; $\mathrm{P}=0.043$; Fig. 2E) were all identified to possess significant prognostic value. Thus, Edmondson grade, AFP levels, age, TNM stage and portal vein invasion were negatively correlated with the survival period.

FAK, $\beta$-catenin and $c$-Met. The different survival rates of the patients with mild or over expression of biomarkers were evaluated. No significant correlations were identified between c-Met expression and overall survival rates (mean survival period, 25 vs. 34 months; $\mathrm{P}=0.254$; Fig. $2 \mathrm{~F}$ ). The Kaplan-Meier survival for patients with high vs. low expression of FAK (mean survival period, 20 vs. 36 months; $\mathrm{P}<0.001$; Fig. $2 \mathrm{G}$ ) and $\beta$-catenin (mean survival period, 24 vs. 36 months; $P=0.003$; Fig. 2H) was demonstrated to be significantly different. 
Table II. Primary antibodies used for immunohistochemical analysis.

\begin{tabular}{llcc}
\hline Antibody & \multicolumn{1}{c}{ Source } & Catalogue no. & Dilution \\
\hline Anti-focal adhesion kinase & Epitomics (Abcam, Cambridge, UK) & ab6094 \\
Rabbit anti-c-Met mAb & Abcam & BD Biosciences (Franklin Lakes, NJ, USA) & $1: 300$ \\
Mouse anti- $\beta$-catenin mAb & 610153 & $1: 250$ \\
\hline
\end{tabular}

mAb, monoclonal antibody.

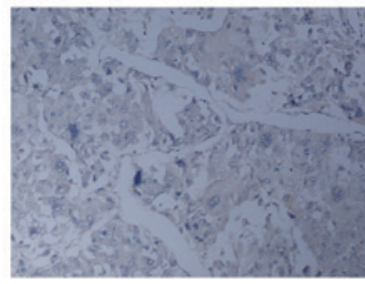

FAK

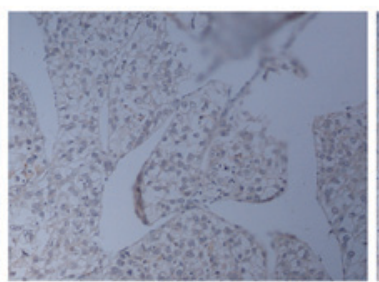

c-Met

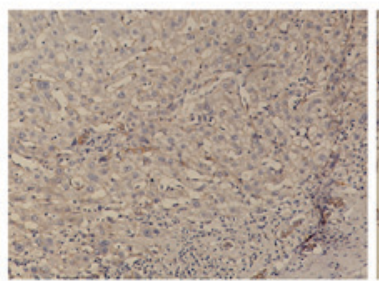

$\beta$-catenin

0

0

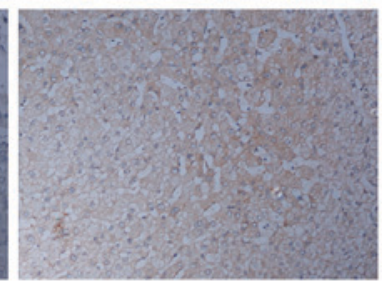

$+1$
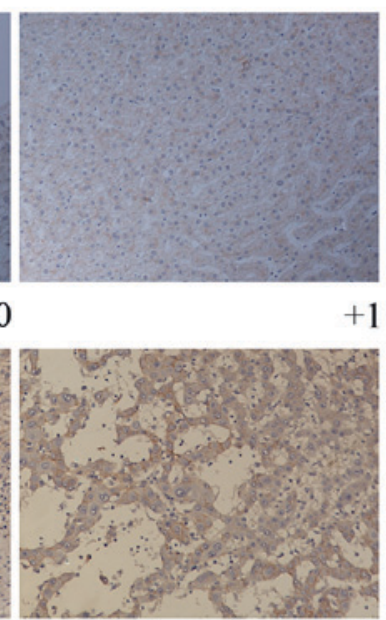

$+1$

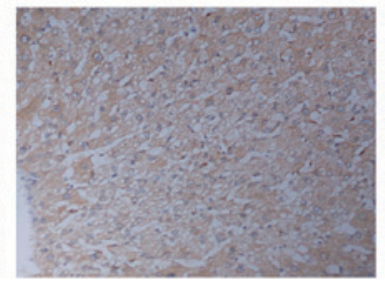

$+2$

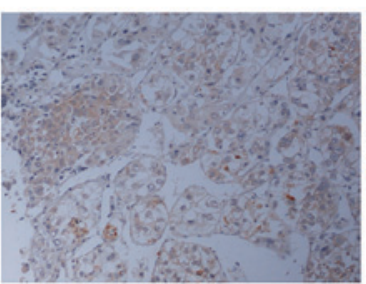

$+2$

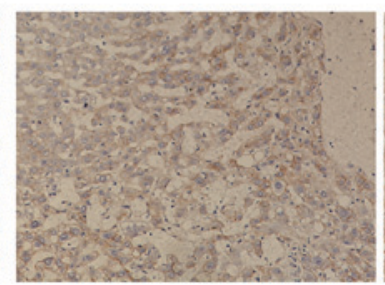

$+2$
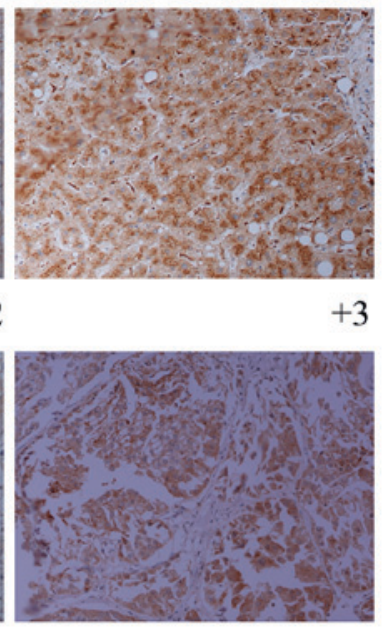

$+3$

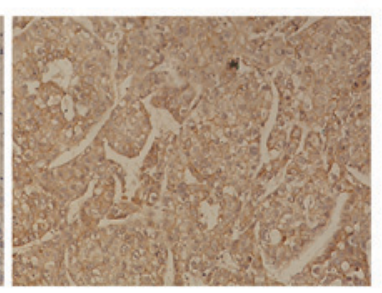

$+3$

Figure 1. Representative images of immunohistochemical staining for FAK, c-Met and $\beta$-catenin in patients with hepatocellular carcinoma. Specimens were categorized according to the proportion of positively stained cells, as follows: $0,<5 \% ; 1+, 6-25 \% ; 2+, 26-50 \%$; and 3+, $>50 \%$ (magnification, x 200 ). FAK, focal adhesion kinase; c-Met, hepatocyte growth factor receptor.

Cox's regression analysis demonstrated that FAK $(\mathrm{P}=0.004)$, $\beta$-catenin $(\mathrm{P}=0.036)$, age $(\mathrm{P}=0.007)$ and $\operatorname{AFP}(\mathrm{P}=0.027)$ were significantly associated with the survival period, whereas, Edmondson grade $(\mathrm{P}=0.083)$ was markedly associated with the survival period (Table V). High FAK expression exhibited a $~ 2.107$-fold higher risk of mortality compared with that of low FAK expression. High $\beta$-catenin expression exhibited a 1.690-fold higher risk of mortality compared with that of low expression. Other factors that influenced the survival period included the age (2.295-fold), AFP levels (1.699-fold) and Edmondson grade (1.632-fold). However, the results of the present study for age as a prognostic factor have yet to be discussed, because it has been demonstrated that the tumor grows at an increased pace in younger people compared with older people in other types of tumor (24-26).

Correlation between FAK, $\beta$-catenin and $c$-Met expression. Following univariate analysis (Table VI), no significant difference was identified between FAK and $\beta$-catenin expression, while a marked difference was demonstrated between c-Met and $\beta$-catenin expression $(\mathrm{P}=0.068)$. However, FAK expression was significantly different compared with c-Met expression $(\mathrm{P}=0.015)$ in 86 patients with HCC. Following correlation analysis (Table VII), $\beta$-catenin was identified to be markedly correlated with c-Met expression $(\mathrm{P}=0.052$; Pearson's $r=0.21)$, but the other comparison, including c-Met vs. FAK ( $\mathrm{P}=0.855$; Pearson's $\mathrm{r}=0.020)$ and FAK vs. $\beta$-catenin $(\mathrm{P}=0.164$; Pearson's $\mathrm{r}=0.151)$, lacked an identifiable outcome.

\section{Discussion}

A variety of molecular events have been identified to be involved in the etiopathogenesis of $\mathrm{HCC}$, including insulin-like growth factors, hepatocyte growth factor and the Wnt/ $\beta$-catenin signaling axis $(27,28)$. Specific signaling pathways include Wnt, insulin like growth factor and mechanistic 
Table III. Correlation between molecular marker overexpression and the clinicopathological characteristics of patients with hepatocellular carcinoma.

\begin{tabular}{|c|c|c|c|c|c|c|c|c|c|}
\hline \multirow{2}{*}{$\begin{array}{l}\text { Clinicopathological } \\
\text { characteristic }\end{array}$} & \multicolumn{3}{|c|}{ FAK } & \multicolumn{3}{|c|}{$\beta$-catenin } & \multicolumn{3}{|c|}{ c-Met } \\
\hline & $\mathrm{L}(\mathrm{n}=47)$ & $\mathrm{H}(\mathrm{n}=39)$ & P-value & $\mathrm{L}(\mathrm{n}=34)$ & $\mathrm{H}(\mathrm{n}=52)$ & P-value & $\mathrm{L}(\mathrm{n}=32)$ & $\mathrm{H}(\mathrm{n}=54)$ & P-value \\
\hline Sex & & & 0.249 & & & 0.632 & & & 0.702 \\
\hline Male & 35 & 33 & & 26 & 42 & & 26 & 42 & \\
\hline Female & 12 & 6 & & 8 & 10 & & 6 & 12 & \\
\hline Age, years & & & 0.647 & & & 0.968 & & & 0.129 \\
\hline$\leq 60$ & 38 & 33 & & 28 & 43 & & 29 & 42 & \\
\hline$>60$ & 9 & 6 & & 6 & 9 & & 3 & 12 & \\
\hline Size, cm & & & 0.164 & & & $<0.001$ & & & 0.012 \\
\hline$<3$ & 16 & 8 & & 17 & 7 & & 14 & 10 & \\
\hline$\leq 3$ & 31 & 31 & & 17 & 45 & & 18 & 44 & \\
\hline HBV infection status & & & 0.588 & & & $<0.001$ & & & 0.919 \\
\hline$(-)$ & 8 & 5 & & 12 & 1 & & 5 & 8 & \\
\hline$(+)$ & 39 & 34 & & 22 & 51 & & 27 & 46 & \\
\hline AFP level ng/ml & & & 0.314 & & & 0.130 & & & 0.014 \\
\hline$<500$ & 28 & 19 & & 22 & 25 & & 23 & 24 & \\
\hline$\geq 500$ & 19 & 20 & & 12 & 27 & & 9 & 30 & \\
\hline Edmondson grade & & & $<0.001$ & & & $<0.001$ & & & 0.001 \\
\hline $\mathrm{I} / \mathrm{II}$ & 41 & 15 & & 30 & 26 & & 28 & 28 & \\
\hline III/IV & 6 & 24 & & 4 & 26 & & 4 & 26 & \\
\hline TMN stage & & & $<0.001$ & & & 0.001 & & & 0.010 \\
\hline $\mathrm{I} / \mathrm{II}$ & 39 & 13 & & 28 & 24 & & 25 & 27 & \\
\hline III/IV & 8 & 26 & & 6 & 28 & & 7 & 27 & \\
\hline Portal vein invasion status & & & $<0.001$ & & & 0.018 & & & 0.032 \\
\hline$(-)$ & 42 & 22 & & 30 & 34 & & 28 & 36 & \\
\hline$(+)$ & 5 & 17 & & 4 & 18 & & 4 & 18 & \\
\hline Cirrhosis status & & & 0.810 & & & 0.058 & & & 0.346 \\
\hline$(-)$ & 11 & 10 & & 12 & 9 & & 6 & 15 & \\
\hline$(+)$ & 36 & 29 & & 22 & 43 & & 26 & 39 & \\
\hline $\begin{array}{l}\text { Microvascular invasion } \\
\text { status }\end{array}$ & & & 0.848 & & & 0.098 & & & 0.605 \\
\hline$(-)$ & 45 & 37 & & 34 & 48 & & 31 & 51 & \\
\hline$(+)$ & 2 & 2 & & 0 & 4 & & 1 & 3 & \\
\hline
\end{tabular}

TNM, tumor-node-metastasis; AFP, $\alpha$-fetoprotein; HPV, hepatitis B virus; FAK, focal adhesion kinase; c-Met, hepatocyte growth factor receptor; $\mathrm{H}$, high expression; L, low expression.

target of rapamycin (29-33). Previous studies identified an association between $\mathrm{c}-$ Met and $\beta$-catenin expression in hepatocarcinogenesis using in vivo models $(12,13,22)$. Shang et al (3) demonstrated that their effects may be regulated by FAK. As the correlation between the three oncoproteins has been established in animal models, their potential prognostic value in patients with HCC was investigated in the present study. Firstly, the correlation between the clinicopathological features of patients with HCC and the expression of the three oncoproteins was assessed. Kaplan-Meier survival and Cox's regression analyses were used to assess their correlation with the survival period. The correlations between the three molecular markers were also analyzed.

FAK is a cytoplasmic protein tyrosine kinase (34). Previous studies have identified FAK overexpression and activation in several advanced-stage solid cancer types $(12,19)$. Furthermore, cancer and stromal cells have been demonstrated to be affected by FAK in the process of carcinogenesis; for example, integrin-FAK signaling activated a number of signaling pathways via phosphorylation and protein-protein interactions to promote tumorigenesis (9-11). In the present study, FAK expression was revealed to be significantly different compared with different Edmondson grades $(\mathrm{P}<0.001)$, 
Table IV. Logistic analysis for the correlation between the overexpression of molecular markers and the clinicopathological parameters of patients with hepatocellular carcinoma ${ }^{\mathrm{a}}$.

A, Correlation between FAK expression and Edmonson grade

\begin{tabular}{lccccr}
\hline Variable & B & SE & Wald & df & P-value \\
\hline Edmonson grade & 1.872 & 0.600 & 9.735 & 1 & 0.002 \\
Constant & -1.872 & 0.758 & 6.102 & 1 & 0.014 \\
\hline
\end{tabular}

B, Correlation between $\beta$-catenin expression and clinicopathological characteristics

\begin{tabular}{lccrrr}
\hline Variable & B & SE & Wald & df & P-value \\
\hline Edmonson grade & 2.242 & 0.813 & 7.597 & 1 & 0.006 \\
Tumor size & 1.635 & 0.624 & 6.875 & 1 & 0.408 \\
HBV infection & 3.787 & 1.247 & 9.224 & 1 & 5.132 \\
Constant & -8.521 & 2.094 & 16.567 & 1 & 0.002 \\
\hline
\end{tabular}

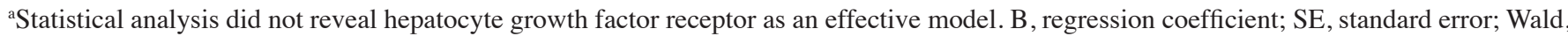
statistic value; df, degree of freedom; FAK, focal adhesion kinase; HPV, hepatitis B virus.

different TNM stages $(\mathrm{P}<0.001)$ and patients with or without portal vein invasion $(\mathrm{P}<0.001)$. Logistic analysis demonstrated a significant correlation between FAK and Edmondson grade $(\mathrm{P}=0.002)$. Following Kaplan-Meier survival curve analysis, different survival rates were identified between subjects with high and low FAK expression (mean survival period, 20 vs. 36 months; $\mathrm{P}<0.001)$. Furthermore, Cox's regression analysis revealed a correlation between FAK expression and the survival period; it appears that patients with high FAK expression have a 2.107 -fold higher risk of mortality compared with that of patients with low FAK expression $(\mathrm{P}=0.004)$. Thus, the results of the present study suggest that FAK is correlated with certain clinicopathological features of patients with HCC. Notably, FAK expression was identified to be correlated with the survival period, indicating its potential prognostic value in patients with HCC.

c-Met tyrosine kinase is a cell surface receptor for hepatocyte growth factor (HGF) (35). HGF is secreted by mesenchymal cells that are regenerated in the liver (35). c-Met activation by HGF can induce cell scattering, invasion, evasion from apoptosis and angiogenesis, thus acting as promoter of cancer dissemination (20). The HGF/c-Met signaling pathway has been demonstrated to simultaneously activate multiple signal transduction pathways that promote cancer cell infiltration (36-41). In addition, genetic mutations of the c-Met receptor and its overexpression have been reported in various cancer types, including papillary renal, pulmonary, gastric and hepatic cancer (36-42). According to the potential role of c-Met in liver regeneration, its correlation with cirrhosis should have been easily identified in the present study; however, no correlation was identified between the two. By contrast, c-Met expression was significantly different compared with that of certain tumor-associated factors such as tumor size $(\mathrm{P}=0.012)$, AFP $(\mathrm{P}=0.014)$, poor histological differentiation (Edmondson grade) $(\mathrm{P}=0.001)$ and TNM stage $(\mathrm{P}=0.010)$. This indicates that $\mathrm{c}$-Met may possess a more specific role than previously considered. Despite successful detection of c-Met expression differences in the specimens, no significant correlation was identified between c-Met expression and the survival period in the Kaplan-Meier survival curve or Cox's regression analyses. Considering these results, it is suggested that the prognostic significance of c-Met in HCC is limited.

$\beta$-catenin protein can be located in the cell membrane, cytoplasm or nucleus (43). In inactivated cells, the majority of $\beta$-catenin is primarily located in the membrane and integrated into the adhesion complex, which is responsible for maintaining cell junctions. The remaining $\beta$-catenin that is free in the cytoplasm binds to a degradation complex and is degraded. Once the Wnt $/ \beta$-catenin signaling pathway is aberrantly activated, membranous expression of $\beta$-catenin is reduced and cytoplasmic degradation of $\beta$-catenin is prevented. This allows free $\beta$-catenin to accumulate in the cytoplasm and translocate to the nucleus, where it interacts with transcription factors of the T-cell factor/lymphoid enhancer factor family to regulate various target genes (31).

Numerous studies have reported that $\beta$-catenin overexpression in the cytoplasm and/or nucleus is correlated with cancer metastasis and poor prognosis (43-51). In the present study, higher Edmondson grade, poor TNM stage and positive portal vein invasion cases were identified to have increased cytoplasmic expression of $\beta$-catenin. Furthermore, univariate analysis confirmed a significant difference and correlation between $\beta$-catenin overexpression, and poor histological differentiation, Edmondson grade $(\mathrm{P}<0.001)$ and TNM stage $(\mathrm{P}=0.001)$. Following multivariate analysis, a significant correlation was identified between $\beta$-catenin overexpression and Edmondson grade $(\mathrm{P}=0.006)$. Other clinicopathological factors such as tumor size $(\mathrm{P}<0.001)$ and HBV infection $(\mathrm{P}<0.001)$ were identified to be significantly associated with $\beta$-catenin expression. $\beta$-catenin demonstrated a significant correlation with the survival period 

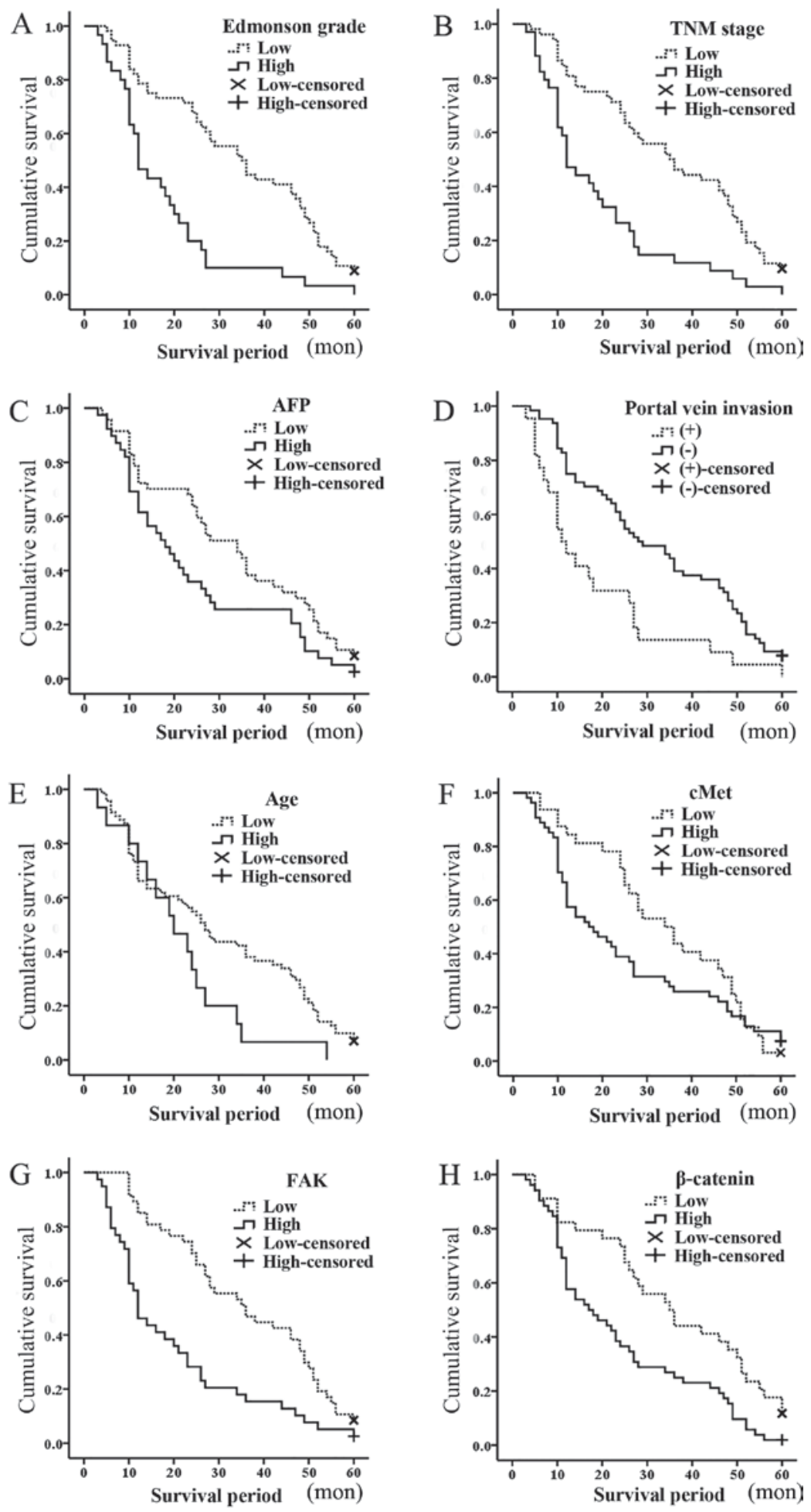

Figure 2. Kaplan-Meier survival curves for patients with hepatocellular carcinoma over 60 months: (A) Mean survival period (months), 18 vs. 34 for Edmonson grade III/IV vs. Edmondson grade I/II, respectively; P<0.001. (B) Mean survival period (months), 19 vs. 35 for TNM stage III/IV vs. TNM stage I/II, respectively; $\mathrm{P}<0.001$. (C) Mean survival period (months), 24 vs. 32 for AFP levels high ( $\geq 500 \mathrm{ng} / \mathrm{ml}$ ) vs. low ( $<500 \mathrm{ng} / \mathrm{ml})$, respectively; $\mathrm{P}=0.038$. (D) Mean survival period (months), 18 vs. 32 for portal vein invasion, positive vs. negative, respectively; $\mathrm{P}=0.001$. (E) Mean survival period (months), 21 vs. 30 for $>60$ vs. $\leq 60$ years, respectively; $\mathrm{P}=0.043$. (F) Mean survival period (months), 25 vs. 34 for c-Met high expression vs. low expression, respectively; $\mathrm{P}=0.254$; (G) Mean survival period (months), 20 vs. 36 for FAK high expression vs. low expression, respectively; $\mathrm{P}<0.001$. (H) Mean survival period (months), 24 vs. 36 for $\beta$-catenin high expression vs. low expression, respectively; $\mathrm{P}=0.003$. Censored refers to the state of the patient at follow-up, whereby 0 means censored and 1 means mortality.; high, high expression; low, low expression; TNM, tumor-node-metastasis; AFP, $\alpha$-fetoprotein; FAK, focal adhesion kinase; c-Met, hepatocyte growth factor receptor.

according to the Kaplan-Meier survival curve (24 vs. $36 \%$; $\mathrm{P}=0.003)$ and Cox's regression $(\mathrm{P}=0.036)$ analyses. Patients with high $\beta$-catenin expression exhibited a 1.690 -fold higher risk of mortality compared with that of patients with low $\beta$-catenin expression. The results of the present study suggest that $\beta$-catenin may be correlated with specific 
Table V. Cox's regression analysis of parameters in patients with hepatocellular carcinoma.

\begin{tabular}{|c|c|c|c|c|c|c|}
\hline Parameter & B & SE & Wald & df & P-value & OR \\
\hline FAK expression & 0.745 & 0.262 & 8.082 & 1 & 0.004 & 2.107 \\
\hline$\beta$-catenin expression & 0.525 & 0.250 & 4.389 & 1 & 0.036 & 1.690 \\
\hline Age & 0.831 & 0.306 & 7.372 & 1 & 0.007 & 2.295 \\
\hline AFP level & 0.530 & 0.239 & 4.918 & 1 & 0.027 & 1.699 \\
\hline Edmonson grade & 0.490 & 0.283 & 2.998 & 1 & 0.083 & 1.632 \\
\hline
\end{tabular}

B, regression coefficient; SE, standard error; Wald, statistic value; df, degree of freedom; FAK, focal adhesion kinase; AFP, $\alpha$-fetoprotein.

Table VI. Correlation between $\beta$-catenin, FAK and c-Met expression in patients with hepatocellular carcinoma.

A, Correlation between $\beta$-catenin and FAK expression $(n=86)$

\begin{tabular}{lccc}
\hline & \multicolumn{2}{c}{$\beta$-catenin } & \\
\cline { 2 - 3 } Variable & $\mathrm{L}(\mathrm{n}=34)$ & $\mathrm{H}(\mathrm{n}=52)$ & P-value \\
\hline FAK expression & & & 0.376 \\
$\mathrm{~L}(\mathrm{n}=47)$ & 21 & 26 & \\
$\mathrm{H}(\mathrm{n}=39)$ & 13 & 26 & \\
\hline
\end{tabular}

B, Correlation between $\beta$-catenin and c-Met expression $(n=86)$

\begin{tabular}{lccc}
\hline & \multicolumn{2}{c}{$\beta$-catenin } & \\
\cline { 2 - 3 } Variable & $\mathrm{L}(\mathrm{n}=34)$ & $\mathrm{H}(\mathrm{n}=52)$ & P-value \\
\hline c-Met expression & & & 0.068 \\
$\mathrm{~L}(\mathrm{n}=32)$ & 17 & 15 & \\
$\mathrm{H}(\mathrm{n}=54)$ & 17 & 37 & \\
\hline
\end{tabular}

C, Correlation between c-Met and FAK expression $(n=86)$

\begin{tabular}{lccc}
\hline \multicolumn{2}{c}{$\mathrm{c}$-Met } & \\
\cline { 2 - 3 } Variable & $\mathrm{L}(\mathrm{n}=34)$ & $\mathrm{H}(\mathrm{n}=52)$ & P-value \\
\hline FAK expression & & & 0.015 \\
$\mathrm{~L}(\mathrm{n}=47)$ & 23 & 24 & \\
$\mathrm{H}(\mathrm{n}=39)$ & 9 & 30 & \\
\end{tabular}

FAK, focal adhesion kinase; c-Met, hepatocyte growth factor receptor; $\mathrm{H}$, high expression; $\mathrm{L}$, low expression.

clinicopathological factors and survival period of patients with HCC. Thus, $\beta$-catenin may potentially be used as a prognostic factor for $\mathrm{HCC}$.

The clinicopathological factors investigated in the current study are generally considered to be correlated with HCC, including sex, HBV infection, liver cirrhosis, tumor size, portal vein invasion, microvascular invasion, Edmondson grade and TNM stage $(23,50,51)$. In the present study, the
Table VII. Correlation between molecular markers in patients with hepatocellular carcinoma.

\begin{tabular}{lccc}
\hline & \multicolumn{3}{c}{ Molecular marker } \\
\cline { 2 - 4 } Molecular marker & c-Met & $\beta$-catenin & FAK \\
\hline c-Met & & 0.210 & 0.020 \\
Pearson's r & 1 & 0.052 & 0.855 \\
$\begin{array}{l}\text { P-value (2-tailed) } \\
\text { No. of patients }\end{array}$ & 86 & 86 & 86 \\
$\begin{array}{l}\text { 3-catenin } \\
\text { Pearson's r }\end{array}$ & 0.210 & 1 & 0.151 \\
$\begin{array}{l}\text { P-value (2-tailed) } \\
\text { No. of patients }\end{array}$ & 0.052 & & 0.164 \\
FAK & 86 & 86 & 86 \\
$\begin{array}{l}\text { Pearson's r } \\
\text { P-value (2-tailed) }\end{array}$ & 0.855 & 0.164 & 1 \\
No. of patients & 86 & 86 & 86 \\
\hline c-Met, hepatocyte growth factor & receptor; FAK, focal adhesion \\
kinase. & & & \\
\hline
\end{tabular}

correlation between these factors and the expression of the three oncoproteins was investigated; in addition, their correlation with survival period was verified. Based on the results obtained, the majority of factors were consistent with general considerations, such as portal vein invasion, Edmondson grade and TNM stage possessing a negative correlation with the survival period in the Kaplan-Meier survival curve analysis, and Edmondson grade serving as an independent risk factor in Cox's regression analysis. However, certain factors, such as age and HBV infection demonstrated controversial outcomes that require further analysis. In the present study, different $\beta$-catenin expression levels were identified in patients that had been infected by HBV vs. non-infected patients. To the best of our knowledge, no correlation between HBV infection and $\beta$-catenin expression has been previously identified. The HBV infection rate among the participants in the present study was relatively high $(73 / 86 ; 85 \%)$, and as only 13 patients were HBV-negative, there may have been selective bias.

Although significant correlations were identified between the three oncoproteins and certain clinicopathological factors, 
no significant correlation was identified among the three oncoproteins themselves following logistic analysis. Thus, further studies on the three molecular markers were performed. Firstly, the differences between each set of two markers were analyzed, and univariate analysis demonstrated a significant difference between FAK and $\beta$-catenin expression $(\mathrm{P}=0.015)$, and a marked difference between c-Met and $\beta$-catenin expression $(\mathrm{P}=0.068)$. Following correlation analysis amongst the three molecular markers, no significant correlation was identified between any pair; however, $\beta$-catenin was identified to be correlated with c-Met $(\mathrm{P}=0.052$; Pearson's $\mathrm{r}=0.21)$. The established association with c-Met and $\beta$-catenin in hepatocarcinogenesis, identified previously $(1,10)$, was consistent with the results of the present study. Although significant differences between FAK and $\beta$-catenin expression were established, their correlation with $\beta$-catenin and c-Met cannot be concluded.

Other established criteria, including poor histological differentiation (Edmondson grade and TNM stage), were in agreement with the general consensus (23,52-54). Apart from different statistical results of c-Met, FAK and $\beta$-catenin, FAK and $\beta$-catenin performed well according to a variety of statistical indicators in the present study. As prognostic predictors, FAK and $\beta$-catenin were effective in the present study; however, coeffectiveness of c-Met and $\beta$-Catenin or their regulation by FAK was not observed in the present study $(3,12,22)$.

Certain clinicopathological factors such as tumor size, cirrhosis and microvascular invasion were not identified to be correlated with a high expression of the FAK, $\beta$-catenin and c-Met. TNM stage, which has been previously demonstrated to be correlated with the survival period, was excluded from the Cox's regression analysis $(23,50,51)$. Although the association between c-Met and $\beta$-catenin expression in HCC was not identified to be significant in the present study, their association should be studied further.

In conclusion, c-Met demonstrated conflicting results regarding its correlation with the clinicopathology and survival period of patients with HCC. As a result, its prognostic value cannot be confirmed by the results of the present study. c-Met displayed variable expression in 86 patients, and was expressed in 54/86 (62.8\%) HCC cases. Although no correlation was identified between the three oncoproteins, FAK and $\beta$-catenin demonstrated promising results regarding their correlations with clinicopathological characteristics and survival period of patients with HCC. The results of the current study suggest that FAK and $\beta$-catenin may be used as prognosis markers of HCC. Considering that single agent or combined chemotherapy were used as treatment for all patients following surgery, and the results of the present study on the prognostic value of FAK and $\beta$-catenin, more aggressive treatments such as TACE, PEI or RFA may be required post-surgery for patients with high FAK and $\beta$-catenin expression.

\section{Acknowledgements}

This work was supported by grants from the National Natural Science Foundation of China (grant nos: 81472253, 81472258, 81572424, 81101862, 81172079, 81072047 and 81201930); the Project of Guangzhou Municipal Science \& Technology Planning (grant nos: 201607010309 and 201607010164) and the Science and Technology Planning Project of Guangdong
Province (grant nos: 2016A020215047, 2017A020215016, 2014A020212083).

\section{References}

1. Torre LA, Bray F, Siegel RL, Ferlay J, Lortet-Tieulent J and Jemal A: Global cancer statistics, 2012. CA Cancer J Clin 65: 87-108, 2015.

2. Kim KH and Choi YK: Long-term survival after resection of hepatocellular carcinoma. Korean J Hepatobiliary Pancreat Surg 16: 98-104, 2012.

3. Shang N, Arteaga M,Zaidi A, Stauffer J, Cotler SJ,Zeleznik-Le NJ, Zhang J and Qiu W: FAK is required for c-Met/ $\beta$-catenin-driven hepatocarcinogenesis. Hepatology 61: 214-226, 2015.

4. Bruix J and Sherman M; Practice Guidelines Committee, American Association for the Study of Liver Diseases: Management of hepatocellular carcinoma. Hepatology 42: 1208-1236, 2005.

5. Clevers $\mathrm{H}$ : Wnt/beta-catenin signaling in development and disease. Cell 127: 469-480, 2006.

6. Zhao X and Guan JL: Focal adhesion kinase and its signaling pathways in cell migration and angiogenesis. Adv Drug Deliv Rev 63: 610-615, 2011.

7. Llovet JM, Ricci S, Mazzaferro V, Hilgard P, Gane E, Blanc JF, de Oliveira AC, Santoro A, Raoul JL, Forner A, et al: Sorafenib in advanced hepatocellular carcinoma. N Engl J Med 359: 378-390, 2008

8. Mitra SK, Hanson DA and Schlaepfer DD: Focal adhesion kinase: In command and control of cell motility. Nat Rev Mol Cell Biol 6: 56-68, 2005.

9. Schaller MD: Cellular functions of FAK kinases: Insight into molecular mechanisms and novel functions. J Cell Sci 123: 1007-1013, 2010.

10. Zhao J and Guan JL: Signal transduction by focal adhesion kinase in cancer. Cancer Metastasis Rev 28: 35-49, 2009.

11. Parsons JT: Focal adhesion kinase: The first ten years. J Cell Sci 116: 1409-1416, 2003.

12. Patil MA, Lee SA, Macias E, Lam ET, Xu C, Jones KD, Ho C, Rodriguez-Puebla $\mathrm{M}$ and Chen X: Role of cyclin D1 as a mediator of c-Met and beta-catenin induced hepatocarcinogenesis. Cancer Res 69: 253-261, 2009.

13. Tward AD, Jones KD, Yant S, Cheung ST, Fan ST, Chen X, Kay MA, Wang R and Bishop JM: Distinct pathways of genomic progression to benign and malignant tumors of the liver. Proc Natl Acad Sci USA 104: 14771-14776, 2007.

14. Schlaepfer DD, Hauck CR and Sieg DJ: Signaling through focal adhesion kinase. Prog Biophys Mol Biol 71: 435-478, 1999.

15. Pylayeva Y, Gillen KM, Gerald W, Beggs HE, Reichardt LF and Giancotti FG: Ras- and PI3K-dependent breast tumorigenesis in mice and humans requires focal adhesion kinase signaling. J Clin Invest 119: 252-266, 2009.

16. Ashton GH, Morton JP, Myant K, Phesse TJ, Ridgway RA, Marsh V, Wilkins JA, Athineos D, Muncan V, Kemp R, et al: Focal adhesion kinase is required for intestinal regeneration and tumorigenesis downstream of Wnt/c-Myc signaling. Dev Cell 19: 259-269, 2010.

17. Lee J, Borboa AK, Chun HB, Baird A and Eliceiri BP: Conditional deletion of the focal adhesion kinase FAK alters remodeling of the blood-brain barrier in glioma. Cancer Res 70: 10131-10140, 2010.

18. Itoh S, Maeda T, Shimada M, Aishima S, Shirabe K, Tanaka S and Maehara Y: Role of expression of focal adhesion kinase in progression of hepatocellular carcinoma. Clin Cancer Res 10: 2812-2817, 2004.

19. Fujii T, Koshikawa K, Nomoto S, Okochi O, Kaneko T, Inoue S, Yatabe Y, Takeda S and Nakao A: Focal adhesion kinase is overexpressed in hepatocellular carcinoma and can be served as an independent prognostic factor. J Hepatol 41: 104-111, 2004.

20. Kaposi-Novak P, Lee JS, Gòmez-Quiroz L, Coulouarn C, Factor VM and Thorgeirsson SS: Met-regulated expression signature defines a subset of human hepatocellular carcinomas with poor prognosis and aggressive phenotype. J Clin Invest 116: 1582-1595, 2006.

21. Cieply B, Zeng G, Proverbs-Singh T, Geller DA and Monga SP: Unique phenotype of hepatocellular cancers with exon-3 mutations in beta-catenin gene. Hepatology 49: 821-831, 2009.

22. Stauffer JK, Scarzello AJ, Andersen JB, De Kluyver RL, Back TC, Weiss JM, Thorgeirsson SS and Wiltrout RH: Coactivation of $\mathrm{AKT}$ and $\beta$-catenin in mice rapidly induces formation of lipogenic liver tumors. Cancer Res 71: 2718-2727, 2011. 
23. Edmondson HA and Steiner PE: Primary carcinoma of the liver: A study of 100 cases among 48,900 necropsies. Cancer 7: 462-503, 1954.

24. Calabrese CT, Adam YG and Volk H: Geriatric colon cancer. Am J Surg 125: 181-184, 1973.

25. Ershler WB, Socinski MA and Greene CJ: Bronchogenic cancer, metastases and aging. J Am Geriatr Soc 31: 673-676, 1983.

26. Ershler WB: Why tumors grow more slowly in old people. J Natl Cancer Inst 77: 837-839, 1986.

27. Breuhahn K, Longerich T and Schirmacher P: Dysregulation of growth factor signaling in human hepatocellular carcinoma. Oncogene 25: 3787-3800, 2006.

28. Farazi PA and DePinho RA: Hepatocellular carcinoma pathogenesis: From genes to environment. Nat Rev Cancer 6: 674-687, 2006

29. Tabor E: Tumor suppressor genes, growth factor genes, and oncogenes in hepatitis B virus-associated hepatocellular carcinoma J Med Virol 42: 357-365, 1994.

30. Rogler CE and Chisari FV: Cellular and molecular mechanisms of hepatocarcinogenesis. Semin Liver Dis 12: 265-278, 1992.

31. Sung CO, Yoo BC, Koh KC, Cho JW and Park CK: Prognostic significance of p53 overexpression after hepatic resection of hepatocellular carcinoma. Korean J Gastroenterol 45: 425-430, 2005.

32. Pang RW and Poon RT: From molecular biology to targeted therapies for hepatocellular carcinoma: The future is now. Oncology 72 (Suppl 1): S30-S44, 2007.

33. Llovet JM and Bruix J: Molecular targeted therapies in hepatocellular carcinoma. Hepatology 48: 1312-1327, 2008.

34. André E and Becker-André M: Expression of an N-terminally truncated form of human focal adhesion kinase in brain. Biochem Biophys Res Commun 190: 140-147, 1993.

35. Fausto N, Campbell JS and Riehle KJ: Liver regeneration. Hepatology 43 (2 Suppl 1): S45-S53, 2006.

36. Schmidt L, Duh FM, Chen F, Kishida T, Glenn G, Choyke P, Scherer SW, Zhuang Z, Lubensky I, Dean M, et al: Germline and somatic mutations in the tyrosine kinase domain of the MET proto-oncogene in papillary renal carcinomas. Nat Genet 16: 68-73, 1997.

37. Schmidt L, Junker K, Weirich G, Glenn G, Choyke P, Lubensky I, Zhuang Z, Jeffers M, Vande Woude G, Neumann H, et al: Two North American families with hereditary papillary renal carcinoma and identical novel mutations in the MET proto-oncogene. Cancer Res 58: 1719-1722, 1998.

38. Park WS, Dong SM, Kim SY, Na EY, Shin MS, Pi JH, Kim BJ, Bae JH, Hong YK, Lee KS, et al: Somatic mutations in the kinase domain of the Met/hepatocyte growth factor receptor gene in childhood hepatocellular carcinomas. Cancer Res 59: 307-310, 1999.

39. Ma PC, Kijima T, Maulik G, et al: c-MET mutational analysis in small cell lung cancer: Novel juxtamembrane domain mutations regulating cytoskeletal functions. Cancer Res 63: 6272-6281, 2003

40. Ma PC, Jagdeesh S, Jagadeeswaran R, Fox EA, Christensen J, Maulik G, Naoki K, Schaefer E, Lader A, Richards W, et al: c-MET expression/activation, functions and mutations in non-small cell lung cancer. Proc Am Assoc Cancer Res 44: 1875, 2004.

41. Lee JH, Han SU, Cho H, Jennings B, Gerrard B, Dean M, Schmidt L, Zbar B and Vande Woude GF: A novel germ line juxtamembrane Met mutation in human gastric cancer. Oncogene 19: 4947-4953, 2000.
42. Christensen JG, Burrows J and Salgia R: c-Met as a target for human cancer and characterization of inhibitors for therapeutic intervention. Cancer Lett 225: 1-26, 2005.

43. Chen Z, He X, Jia M, Liu Y, Qu D, Wu D, Wu P, Ni C, Zhang Z, Ye J, et al: $\beta$-catenin overexpression in the nucleus predicts progress disease and unfavourable survival in colorectal cancer: A meta-analysis. PLoS One 8: e63854, 2013.

44. Gough NR: Focus issue: Wnt and beta-catenin signaling in development and disease. Sci Signal 5: eg2, 2012.

45. Inagawa $\mathrm{S}$, Itabashi $\mathrm{M}$, Adachi $\mathrm{S}$, Kawamoto $\mathrm{T}$, Hori $\mathrm{M}$, Shimazaki J, Yoshimi F and Fukao K: Expression and prognostic roles of beta-catenin in hepatocellular carcinoma: Correlation with tumor progression and postoperative survival. Clin Cancer Res 8: 450-456, 2002.

46. Liu L, Zhu XD, Wang WQ, Shen Y, Qin Y, Ren ZG, Sun HC and Tang ZY: Activation of beta-catenin by hypoxia in hepatocellular carcinoma contributes to enhanced metastatic potential and poor prognosis. Clin Cancer Res 16: 2740-2750, 2010.

47. Lee JM, Yang J, Newell P, Singh S, Parwani A, Friedman SL, Nejak-Bowen KN and Monga SP: $\beta$-Catenin signaling in hepatocellular cancer: Implications in inflammation, fibrosis, and proliferation. Cancer Lett 343: 90-97, 2014.

48. Jin J, Jung HY, Wang Y, Xie J, Yeom YI, Jang JJ and Lee KB: Nuclear expression of phosphorylated TRAF2- and NCK-interacting kinase in hepatocellular carcinoma is associated with poor prognosis. Path Res Pract 210: 621-627, 2014.

49. Zulehner G, Mikula M, Schneller D, van Zijl F, Huber H, Sieghart W, Grasl-Kraupp B, Waldhör T, Peck-Radosavljevic M, Beug $\mathrm{H}$ and Mikulits W: Nuclear beta-catenin induces an early liver progenitor phenotype in hepatocellular carcinoma and promotes tumor recurrence. Am J Pathol 176: 472-481, 2010.

50. Liver cancer study group of Japan: The general rules for the clinical and pathological study of primary liver cancer. 3rd edition. Kanehara Shuppan, Tokyo, 1992.

51. Sumie S, Kuromatsu R, Okuda K, Ando E, Takata A, Fukushima N, Watanabe Y, Kojiro M and Sata M: Microvascular invasion in patients with hepatocellular carcinoma and its predictable clinicopathological factors. Ann Surg Oncol 15: 1375-1382, 2008.

52. Minagawa M, Ikai I, Matsuyama Y, Yamaoka $Y$ and Makuuchi M: Staging of hepatocellular carcinoma: Assessment of the Japanese TNM and AJCC/UICC TNM systems in a cohort of 13,772 patients in Japan. Ann Surg 245: 909-922, 2007.

53. Henderson J, Sherman M, Tavill A, Abecassis M, Chejfec G and Gramlich T: AHPBA/AJCC consensus conference on staging of hepatocellular carcinoma: Consensus statement. $\mathrm{HPB}$ (Oxford) 5 : 243-250, 2003.

54. Leung TW, Tang AM,Zee B, Lau WY, Lai PB, Leung KL, Lau JT, Yu SC and Johnson PJ: Construction of the Chinese University Prognostic Index for hepatocellular carcinoma and comparison with the TNM staging system, the Okuda staging system, and the Cancer of the Liver Italian Program staging system: A study based on 926 patients. Cancer 94: 1760-1769, 2002. 